Supporting lnformation

to

\title{
Mechanochemical Synthesis of Supported Bimetallic Catalysts
}

Jacopo De Bellis, Michael Felderhoff, and Ferdi Schüth*

Department of Heterogeneous Catalysis, Max-Planck-Institut für Kohlenforschung, Kaiser-Wilhelm-Platz 1, D-4547o Mülheim an der Ruhr, Germany.

* Corresponding Author (e-mail: schueth@kofo.mpg.de) 


\begin{tabular}{|c|c|c|c|c|c|c|c|c|c|}
\hline \multirow[b]{2}{*}{$\mathbf{M}_{1}, \mathbf{M}_{2}$} & \multirow[b]{2}{*}{ No. S } & \multicolumn{3}{|c|}{ Physical Mixture } & \multicolumn{5}{|c|}{ Milled Powder } \\
\hline & & $\mathbf{w t} \% \mathrm{Au}$ & $w t \% M_{2}$ & $\operatorname{mol} \mathrm{Au} / \mathrm{M}_{2}$ & $\mathbf{w t} \% \mathrm{Au}$ & $w t \% M_{2}$ & $\operatorname{mol} \mathrm{Au} / \mathrm{M}_{2}$ & $w t \% F e$ & wt $\% \mathrm{Cr}$ \\
\hline \multirow{2}{*}{$\varnothing$} & $\mathrm{S} 1$ & - & - & - & - & - & - & 6.7 & 1.1 \\
\hline & $\mathrm{S}_{2}$ & - & - & - & - & - & - & $7 \cdot 4$ & 1.3 \\
\hline \multirow{2}{*}{$\mathrm{Au}$} & $\mathrm{S} 1$ & 3.6 & - & - & $3 \cdot 3$ & - & - & 6.9 & 1.2 \\
\hline & $\mathrm{S}_{2}$ & 3.6 & - & - & $3 \cdot 3$ & - & - & 6.6 & 1.2 \\
\hline \multirow{2}{*}{$\mathrm{Au}, \mathrm{Pd}$} & $\mathrm{S}_{1}$ & $3 \cdot 3$ & 1.7 & 1.0 & 2.9 & 1.4 & 1.1 & 6.5 & 1.0 \\
\hline & $\mathrm{S}_{2}$ & 3.2 & 1.8 & 1.0 & 3.0 & 1.6 & 1.0 & 5.8 & 1.1 \\
\hline \multirow{2}{*}{$\mathrm{Au}, \mathrm{Cu}$} & $\mathrm{S} 1$ & 3.8 & 1.2 & 1.0 & $3 \cdot 5$ & 1.2 & 0.9 & 6.1 & 1.1 \\
\hline & $\mathrm{S}_{2}$ & 3.8 & 1.2 & 1.0 & 3.5 & 1.1 & 1.0 & 6.3 & 1.0 \\
\hline
\end{tabular}

Table S1. Metal loadings used for different preparations ( $\mathrm{S}_{1}$ or $\mathrm{S}_{2}$ ) of selected MgO-supported catalysts. In detail, initial metal loadings are compared to the values found for the samples after $3.5 \mathrm{~h}$ of ball milling via EDX bulk analysis (SEM). In addition, the levels of $\mathrm{Fe}$ and $\mathrm{Cr}$ in the milled powders, which result from some abrasion of milling capsule and media, are presented. Ni and Mn were also detected in trace amounts.

\begin{tabular}{|c|c|c|c|c|c|c|c|c|c|}
\hline \multirow[b]{2}{*}{$\mathbf{M}_{1}, \mathbf{M}_{2}$} & \multirow[b]{2}{*}{ No. S } & \multicolumn{3}{|c|}{ Physical Mixture } & \multicolumn{5}{|c|}{ Milled Powder } \\
\hline & & wt $\% \mathrm{Au}$ & $w t \% M_{2}$ & mol Au / $\mathbf{M}_{2}$ & $\mathbf{w t} \% \mathrm{Au}$ & $w t \% M_{2}$ & $\operatorname{mol} \mathrm{Au} / \mathrm{M}_{2}$ & $w t \% \mathrm{Fe}$ & $w_{t} \% \mathrm{Cr}$ \\
\hline \multirow{2}{*}{$\varnothing$} & $S_{1}$ & - & - & - & - & - & - & 12.0 & 2.0 \\
\hline & $\mathrm{S}_{2}$ & - & - & - & - & - & - & 12.5 & 2.0 \\
\hline \multirow{2}{*}{$\mathrm{Au}$} & $S_{1}$ & 3.6 & - & - & 2.1 & - & - & 10.6 & 1.8 \\
\hline & $\mathrm{S}_{2}$ & 3.6 & - & - & 2.1 & - & - & 10.8 & 1.8 \\
\hline \multirow{2}{*}{$\mathrm{Au}, \mathrm{Pd}$} & $\mathrm{S} 1$ & 3.2 & 1.8 & 1.0 & 2.2 & 1.3 & 0.9 & 12.8 & 2.0 \\
\hline & S2 & 3.2 & 1.8 & 1.0 & 1.8 & 1.3 & 0.8 & 11.8 & 2.0 \\
\hline \multirow{2}{*}{$\mathrm{Au}, \mathrm{Cu}$} & $\mathrm{S}_{1}$ & 3.8 & 1.2 & 1.0 & 2.7 & 1.1 & 0.8 & 11.4 & 1.9 \\
\hline & $\mathrm{S}_{2}$ & 3.8 & 1.2 & 1.0 & 1.9 & 1.1 & 0.6 & 11.6 & 2.0 \\
\hline
\end{tabular}

Table S2. Metal loadings used for different preparations ( $\mathrm{S}_{1}$ or $\mathrm{S}_{2}$ ) of selected YSZ-supported catalysts. In detail, initial metal loadings are compared to the values found for the samples after $3.5 \mathrm{~h}$ of ball milling via EDX bulk analysis (SEM). In addition, the levels of $\mathrm{Fe}$ and $\mathrm{Cr}$ in the milled powders, which result from some abrasion of milling capsule and media, are presented. Ni and Mn were also detected in trace amounts. 


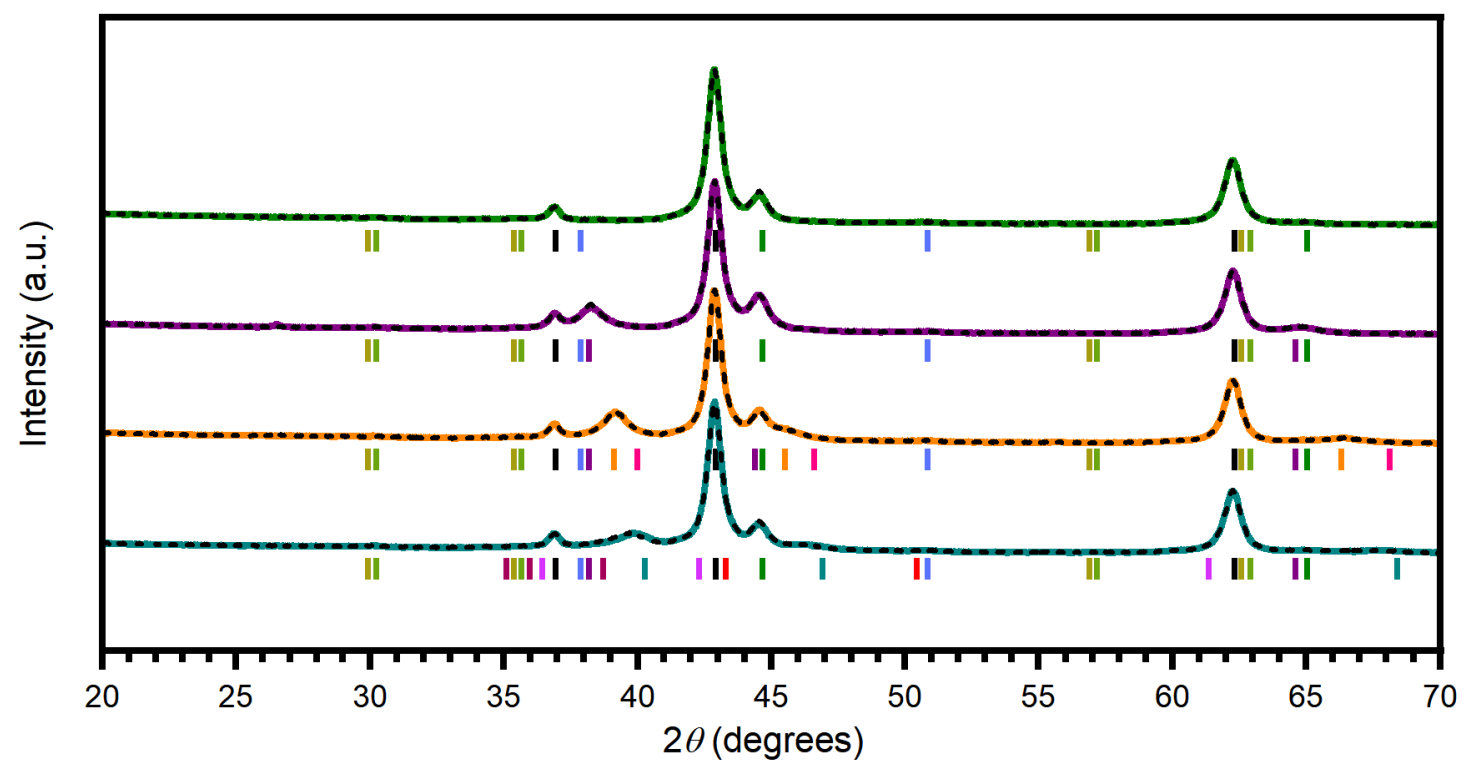

Figure S1. From top to bottom, the XRD patterns of $\mathrm{MgO}, \mathrm{Au} / \mathrm{MgO}, \mathrm{Au}-\mathrm{Pd} / \mathrm{MgO}$, and $\mathrm{Au}-\mathrm{Cu} / \mathrm{MgO}$, respectively. Solid and dotted lines correlate to different preparations of given materials ( $\mathrm{S}_{1}$ and $\mathrm{S}_{2}$, respectively). In Figure 1 of the main document, the XRD patterns of the S1-series of samples are reproduced. Reference peaks color guide: $\bullet \mathrm{MgO}, \bullet \mathrm{Mg}(\mathrm{OH})_{2}$, $\bullet \mathrm{Fe}, \bullet \mathrm{MgFe}_{2} \mathrm{O}_{4}, \bullet \mathrm{Fe}_{3} \mathrm{O}_{4}, \bullet \mathrm{Au}, \bullet \mathrm{Au}-\mathrm{Pd}, \bullet \mathrm{Pd}, \bullet \mathrm{Au}-\mathrm{Cu}, \bullet \mathrm{Cu}, \bullet \mathrm{CuO}, \bullet \mathrm{CuO}$.

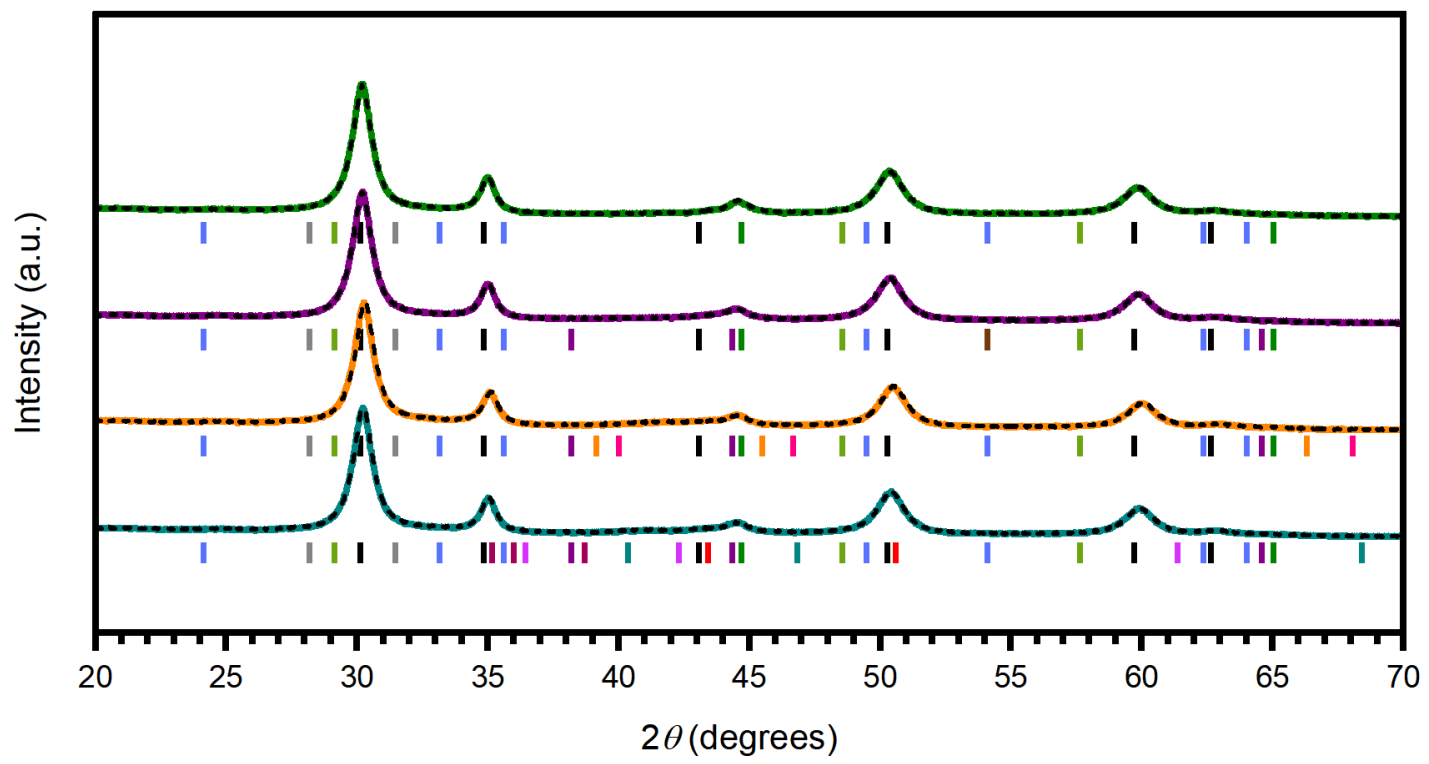

Figure S2. From top to bottom, the XRD patterns of YSZ, Au/YSZ, Au-Pd/ YSZ, and Au-Cu/ YSZ, respectively. Solid and dotted lines correlate to different preparations of given materials ( $\mathrm{S}_{1}$ and $\mathrm{S}_{2}$, respectively). Reference peaks color guide: $\bullet$ $\mathrm{YSZ}, \bullet \mathrm{m}-\mathrm{ZrO}_{2}, \bullet \mathrm{Y}_{2} \mathrm{O}_{3}, \bullet \mathrm{Fe}, \bullet \mathrm{Fe}_{2} \mathrm{O}_{3}, \bullet \mathrm{Au}, \bullet \mathrm{Au}-\mathrm{Pd}, \bullet \mathrm{Pd}, \bullet \mathrm{Au}-\mathrm{Cu}, \bullet \mathrm{Cu}, \bullet \mathrm{CuO}, \bullet \mathrm{CuO}$. 


\begin{tabular}{|c|c|c|c|c|c|c|c|}
\hline \multirow[t]{2}{*}{$\mathbf{M}_{1}, \mathbf{M}_{2}$} & \multirow[t]{2}{*}{ No. S } & \multirow{2}{*}{$\underset{(\mathrm{EDX})}{\mathbf{m o l ~ A u} / \mathbf{M}_{\mathbf{2}}}$} & \multicolumn{3}{|c|}{ Position Diffraction Lines } & \multirow{2}{*}{$\begin{array}{c}\text { mol Au / } \mathbf{M}_{\mathbf{2}} \\
(\mathrm{XRD})\end{array}$} & \multirow[t]{2}{*}{$\Delta$ at $\% M_{2}$} \\
\hline & & & $\left(\begin{array}{lll}1 & 1 & 1\end{array}\right)$ & $\left(\begin{array}{lll}2 & 0 & 0\end{array}\right)$ & $\left(\begin{array}{lll}2 & 2 & 0\end{array}\right)$ & & \\
\hline \multirow{2}{*}{$\mathrm{Au}, \mathrm{Pd}$} & $\mathrm{S}_{1}$ & 1.1 & $\begin{array}{l}39.14^{\circ} \\
\left(39.08^{\circ}\right)\end{array}$ & $\begin{array}{c}45 \cdot 41^{\circ} \\
\left(45 \cdot 44^{\circ}\right)\end{array}$ & $\begin{array}{c}66.34^{\circ} \\
\left(66.22^{\circ}\right)\end{array}$ & 1.1 & - \\
\hline & $\mathrm{S}_{2}$ & 1.0 & $\begin{array}{c}39.15^{\circ} \\
\left(39.13^{\circ}\right)\end{array}$ & $\begin{array}{c}45 \cdot 45^{\circ} \\
\left(45 \cdot 50^{\circ}\right)\end{array}$ & $\begin{array}{c}66.37^{\circ} \\
\left(66.30^{\circ}\right)\end{array}$ & 1.0 & - \\
\hline \multirow{2}{*}{$\mathrm{Au}, \mathrm{Cu}$} & $\mathrm{S}_{1}$ & 0.9 & $\begin{array}{c}39.88^{\circ} \\
\left(40.40^{\circ}\right)\end{array}$ & $\begin{array}{c}46.19^{\circ} \\
\left(46.99^{\circ}\right)\end{array}$ & $\begin{array}{c}67.69^{\circ} \\
\left(68.64^{\circ}\right)\end{array}$ & 1.4 & $-30 \%$ \\
\hline & $\mathrm{S}_{2}$ & 1.0 & $\begin{array}{c}39.65^{\circ} \\
\left(40.26^{\circ}\right)\end{array}$ & $\begin{array}{c}45.59^{\circ} \\
\left(46.83^{\circ}\right)\end{array}$ & $\begin{array}{c}67.22^{\circ} \\
\left(68.39^{\circ}\right)\end{array}$ & 1.7 & $-40 \%$ \\
\hline
\end{tabular}

Table S3. The metal-to-metal molar ratio in the bulk of MgO-based samples (EDX) is compared to the ratio found in the alloyed (supported) nanoparticles as determined from the position of the reflection maxima (fitting of XRD pattern). Under Position Diffraction Lines, the reflection maxima resulting from the fitting of experimental XRD patterns (upper values) are compared to calculated reflection maxima considered metal-to-metal molar ratios found via EDX bulk analysis (lower values, in parentheses). The deviation from bulk values is estimated. S1 and S2 refer to different batches of given materials. 
(a)
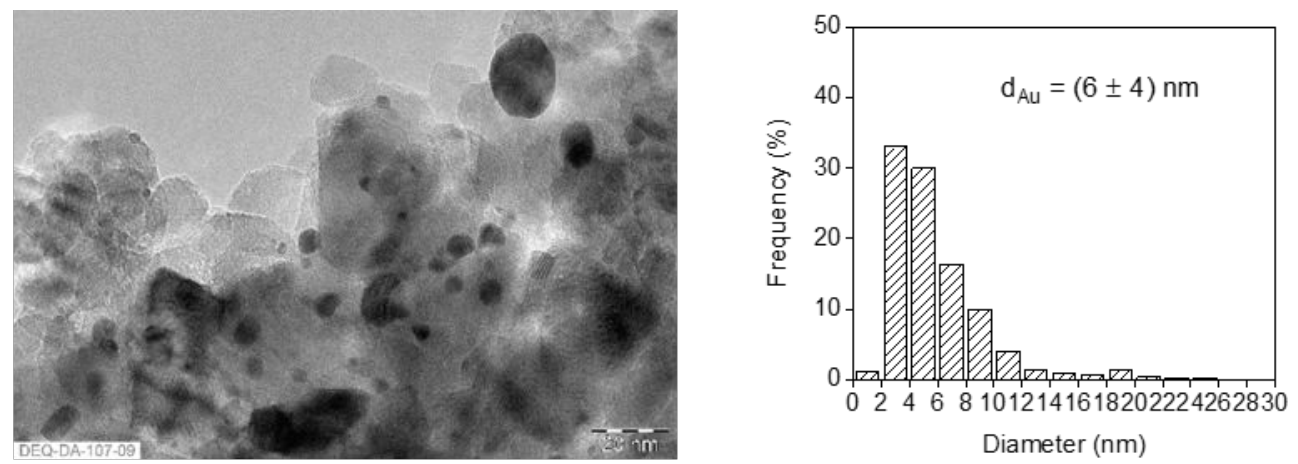

(b)
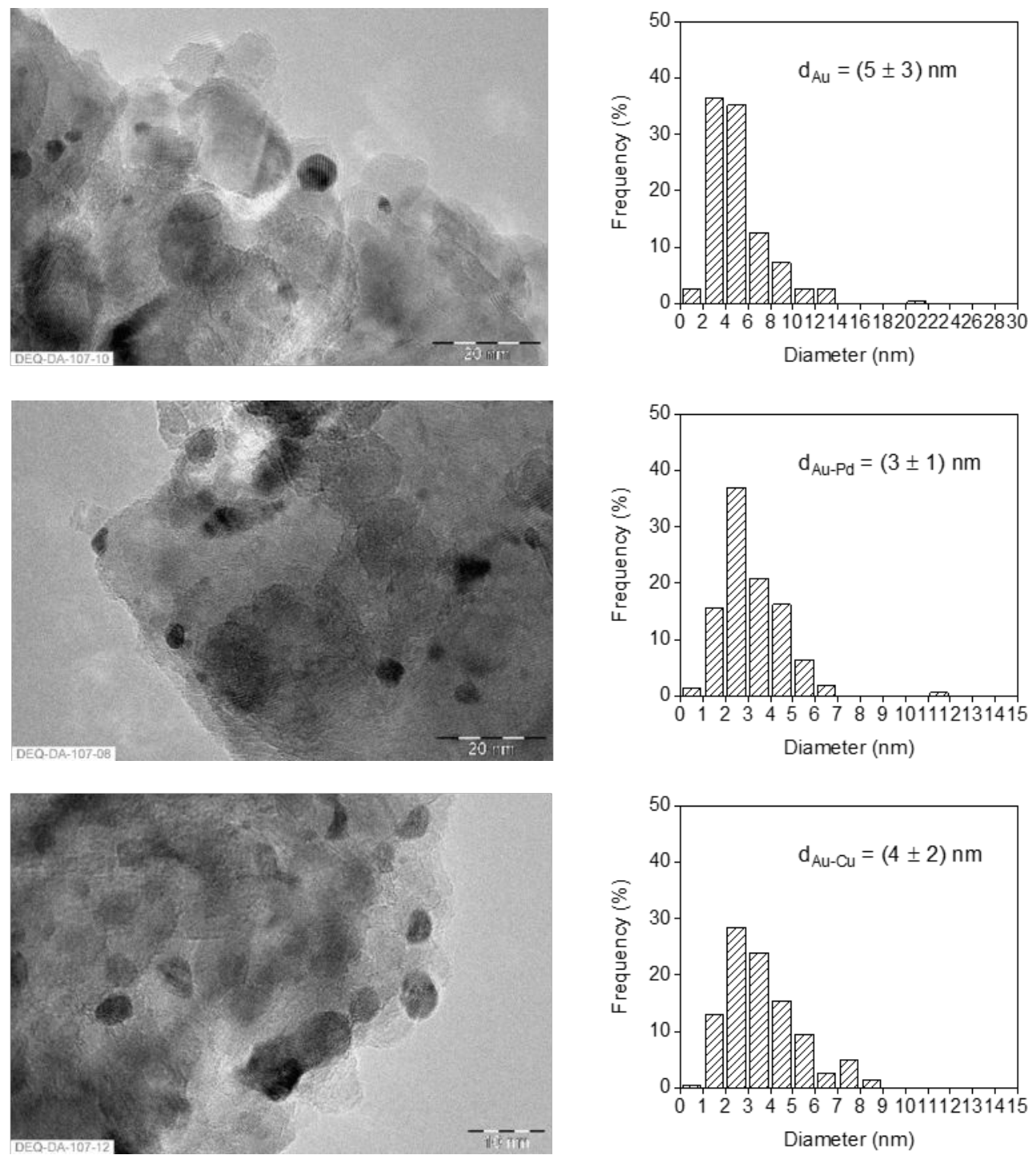

Figure $\mathrm{S}_{3}$. On the left, representative TEM micrographs of $\mathrm{Au} / \mathrm{MgO}\left(\mathrm{S}_{1}, \mathrm{a}\right), \mathrm{Au} / \mathrm{MgO}\left(\mathrm{S}_{2}, \mathrm{~b}\right), \mathrm{Au}-\mathrm{Pd} / \mathrm{MgO}\left(\mathrm{S}_{2}, \mathrm{c}\right)$, and $\mathrm{Au}-$ $\mathrm{Cu} / \mathrm{MgO}\left(\mathrm{S}_{2}, \mathrm{~d}\right)$. S1 and $\mathrm{S}_{2}$ correspond to independent batches of a given material. On the right, the corresponding particle size distributions as histograms (average particle size and related standard deviation are attached). The results of the study carried out on $\mathrm{Au}-\mathrm{Pd} / \mathrm{MgO}\left(\mathrm{S}_{1}\right)$ and $\mathrm{Au}-\mathrm{Cu} / \mathrm{MgO}\left(\mathrm{S}_{1}\right)$ are provided in the main document (Figure 2). 
(a)

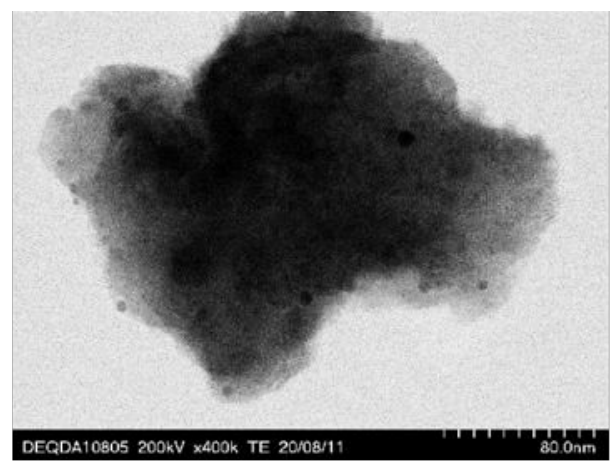

(b)

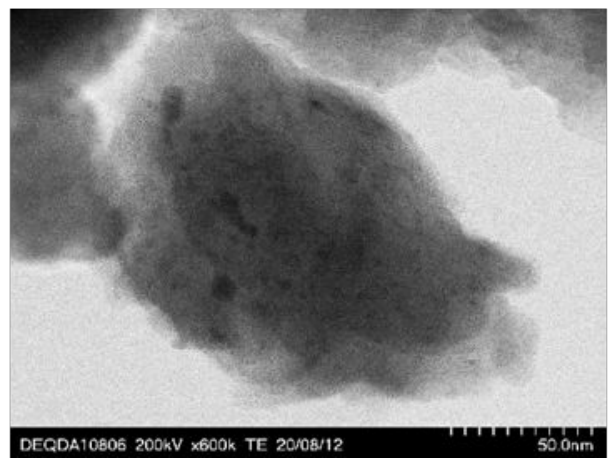

(c)

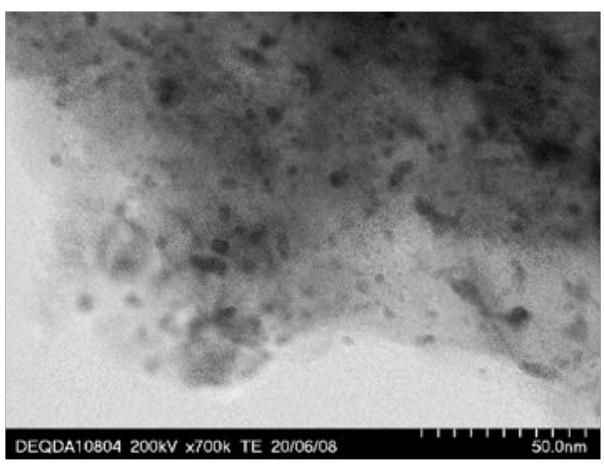

(d)

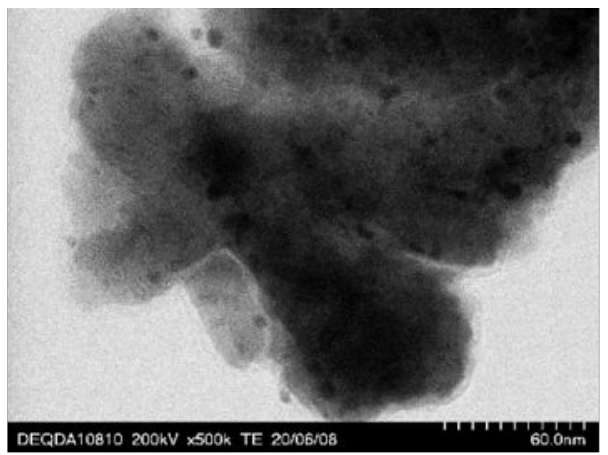

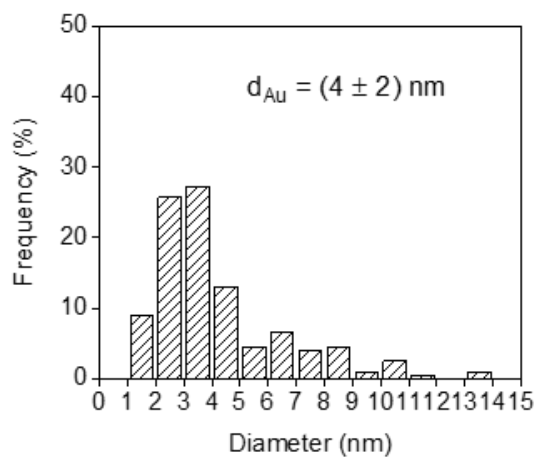
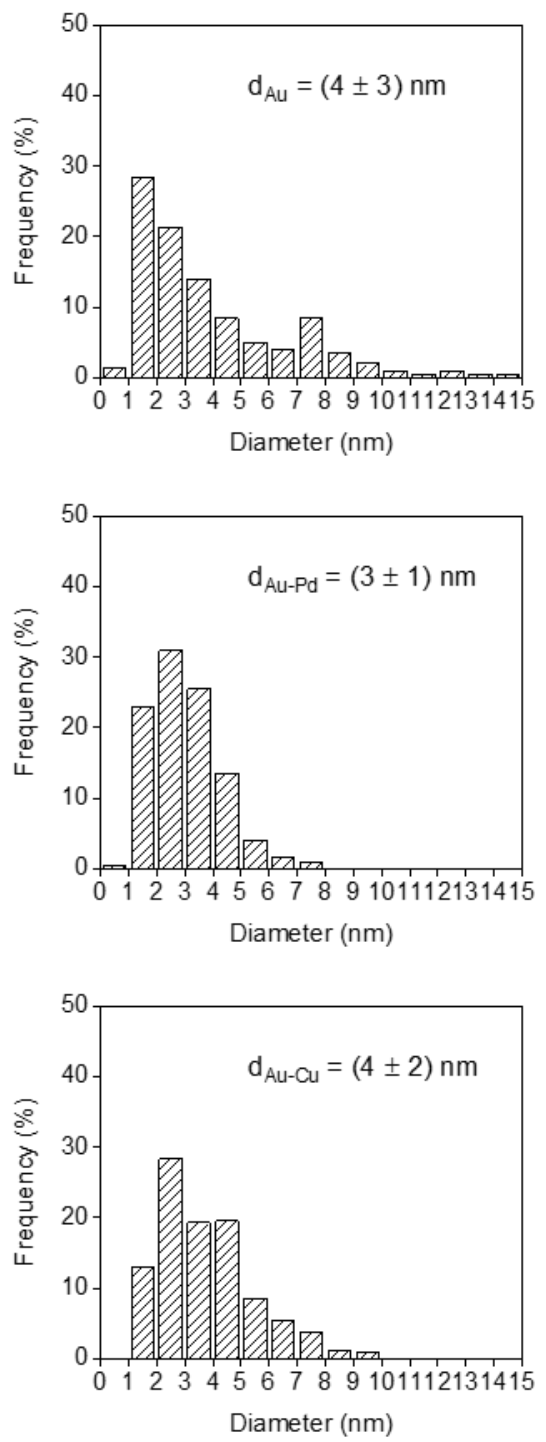

Figure S4. On the left, representative HR-TEM micrographs of Au/YSZ (S1, a), Au/YSZ (S2, b), Au-Pd/YSZ (S2, c), and Au$\mathrm{Cu} / \mathrm{YSZ}\left(\mathrm{S}_{2}, \mathrm{~d}\right)$ as microtomes. S1 and $\mathrm{S}_{2}$ correspond to independent batches of a given material. On the right, the corresponding particle size distributions as histograms. Low contrast between the nanoparticles and the support prevented small particle sizes from being correctly assigned so that average sizes were eventually overestimated. The results of the study carried out on $\mathrm{Au}-\mathrm{Pd} / \mathrm{YSZ}\left(\mathrm{S}_{1}\right)$ and $\mathrm{Au}-\mathrm{Cu} / \mathrm{YSZ}\left(\mathrm{S}_{1}\right)$ are provided in the main document (Figure 3 ). 

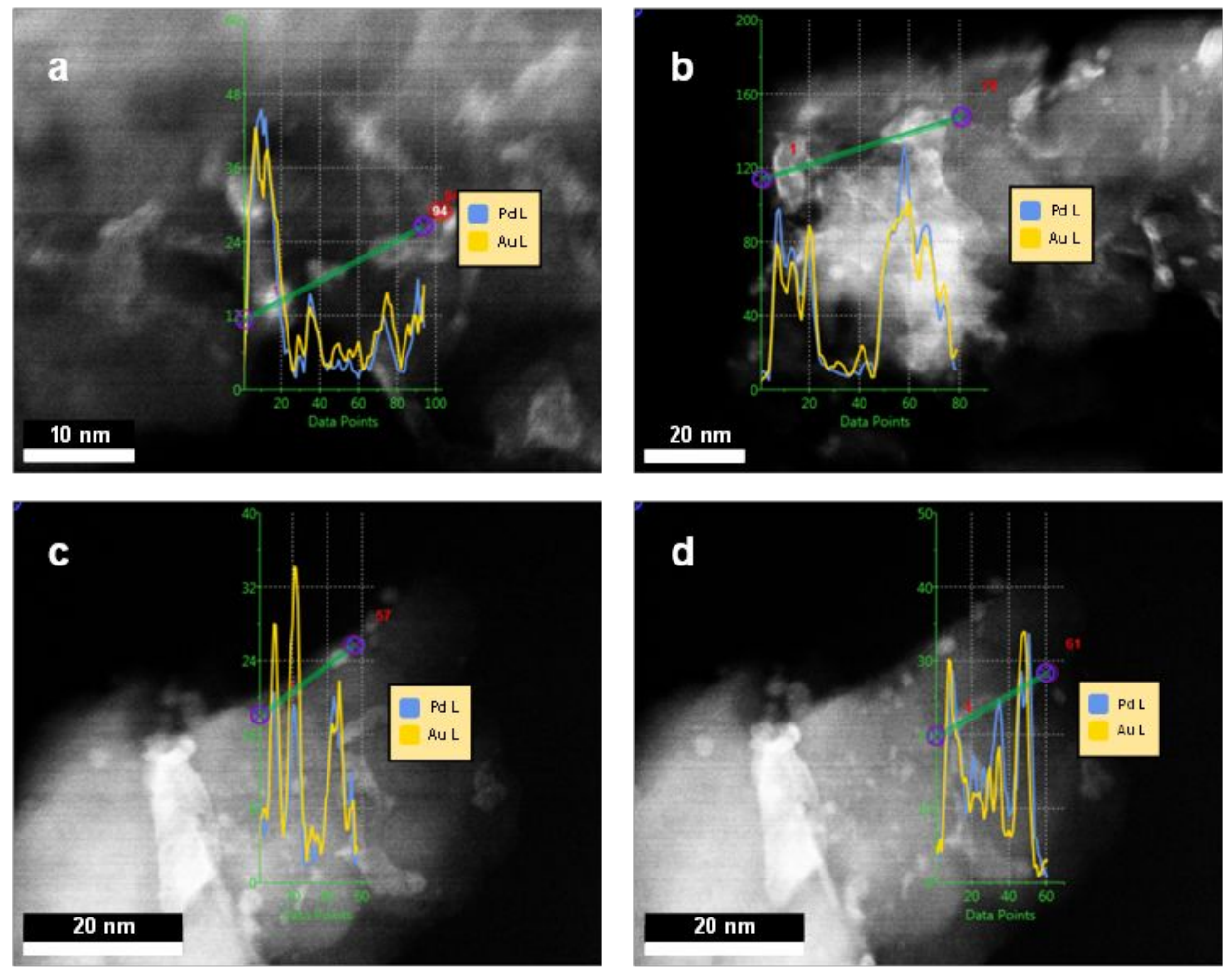

Figure S5. Series of EDX line scans performed over selected Au-Pd nanoparticles supported on YSZ. Intensity plots and color guides are attached. The signal intensity is plotted against the relative position along the drawn line (in projection) where the signal was measured. Detail (c) is reproduced in the main document as Figure $4 a$. 

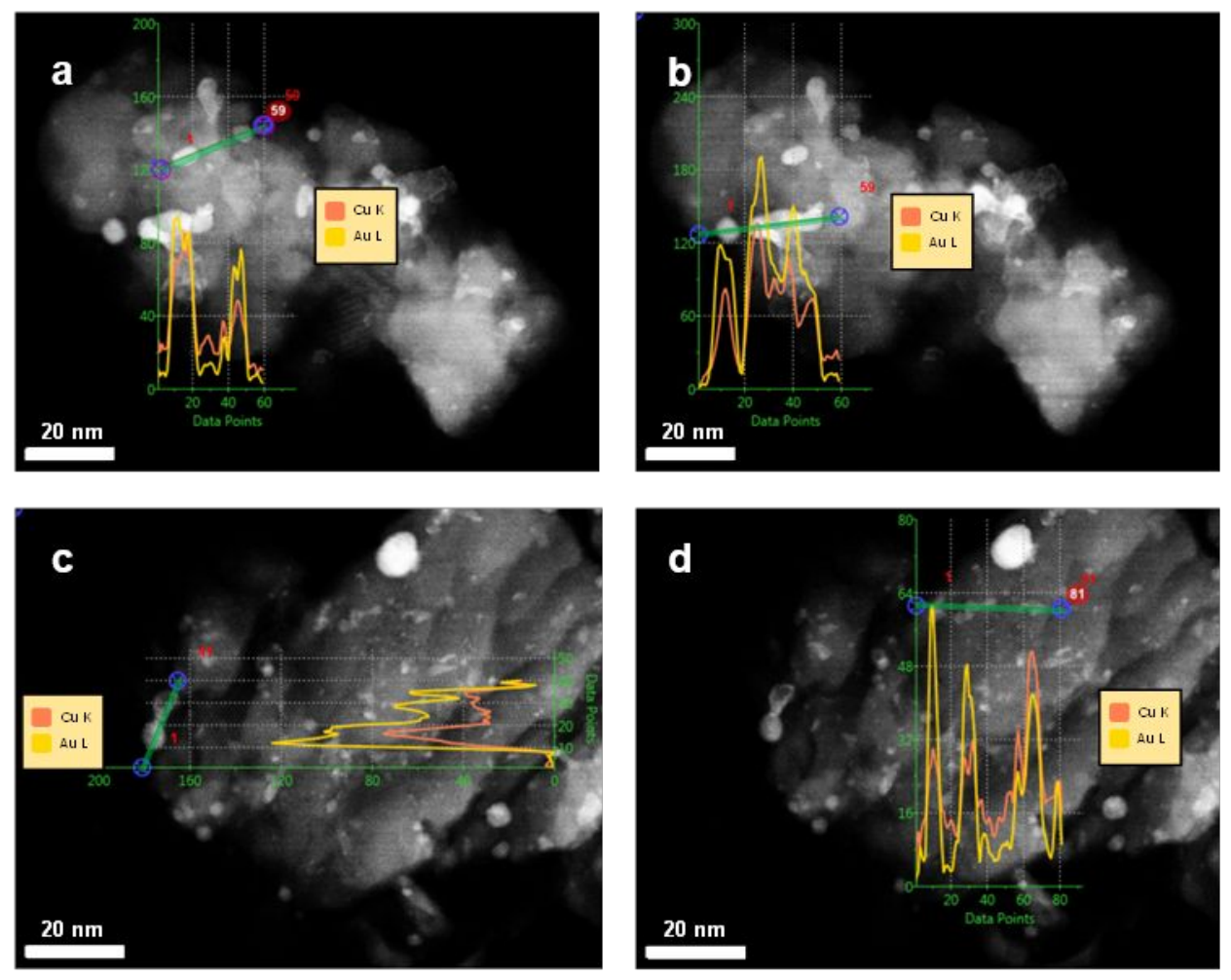

Figure S6. Series of EDX line scans performed over selected Au-Cu nanoparticles supported on YSZ. Intensity plots and color guides are attached. The signal intensity is plotted against the relative position along the drawn line (in projection) where the signal was measured. Detail (d) is reproduced in the main document as Figure $4 \mathrm{~b}$. 

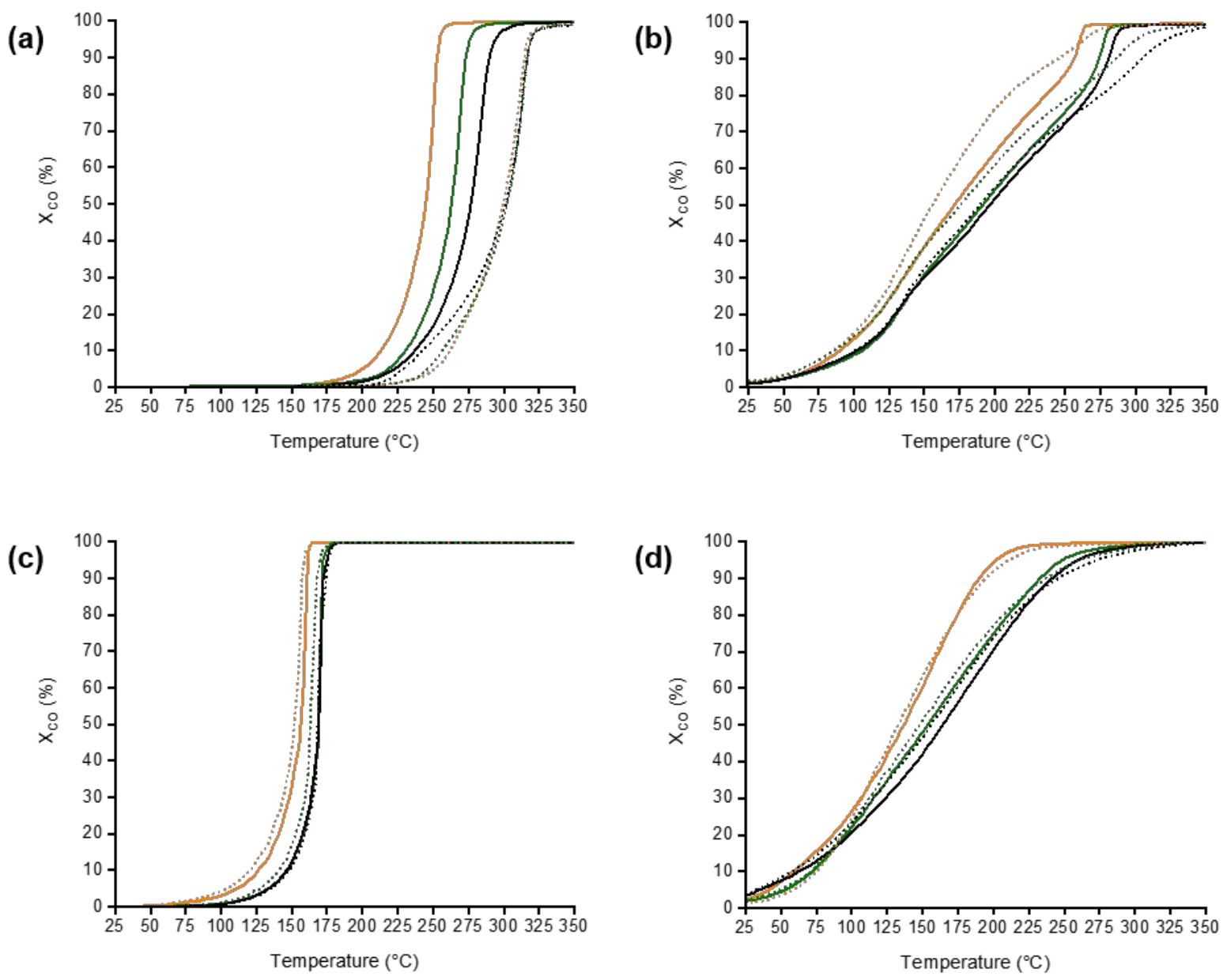

Figure $\mathrm{S}_{7}$. Conversion curves in $\mathrm{CO}$ oxidation for $\mathrm{MgO}(\mathrm{a}), \mathrm{Au} / \mathrm{MgO}$ (b), $\mathrm{Au}-\mathrm{Pd} / \mathrm{MgO}$ (c), and $\mathrm{Au}-\mathrm{Cu} / \mathrm{MgO}$ (d) measured during the heating part of the catalytic cycle ( $1^{\text {st }}$ run, in orange $\rightarrow 2^{\text {nd }}$ run, green $\rightarrow 3^{\text {rd }}$ run, black). For each system, the catalytic activities of two different samples (i.e., independent batches) are represented by solid lines ( $\left.\mathrm{S}_{1}\right)$ or dotted lines (S2). Detail (c) and (d) are partly reproduced in the main document (the catalytic performance of the S1-series of sample is shown only) as Figure $5 a$ and Figure $5 b$, respectively. 
(a)

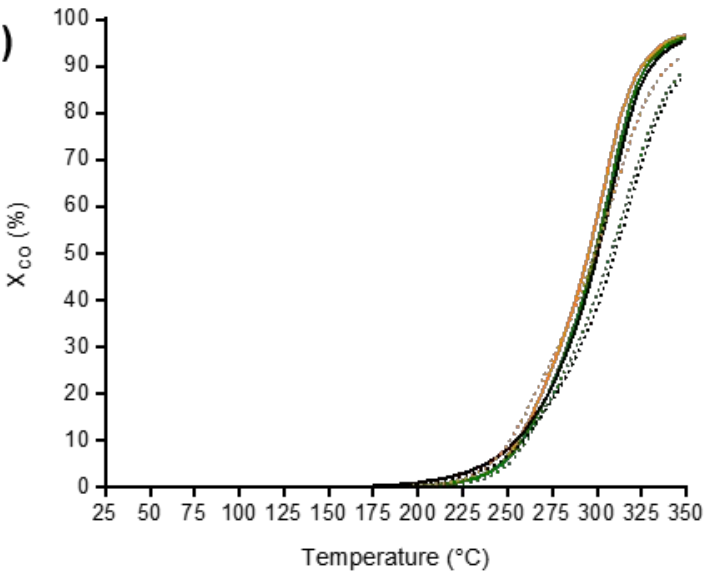

(c)

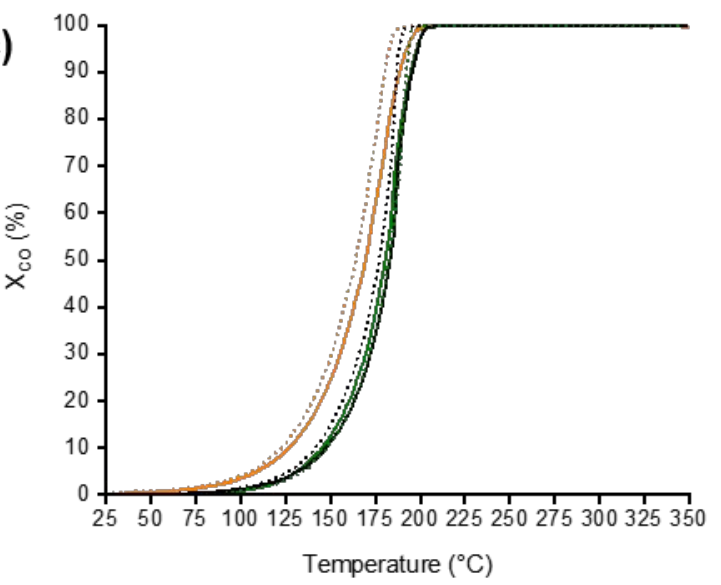

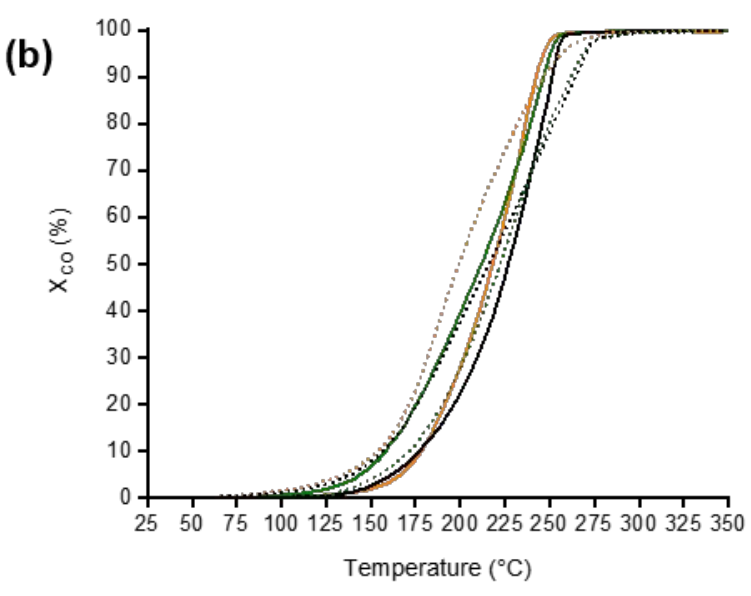

(d)

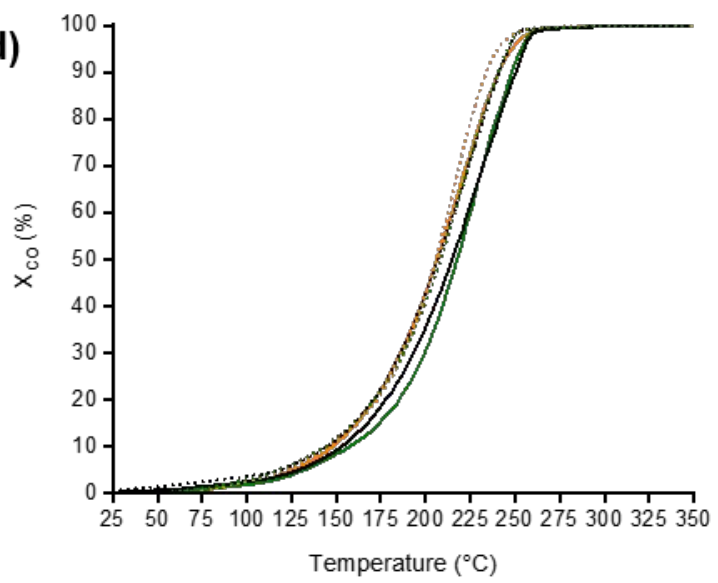

Figure S8. Conversion curves in CO oxidation of YSZ (a), Au/YSZ (b), Au-Pd/YSZ (c), and Au-Cu/YSZ (d) measured during the heating part of the catalytic cycle ( $1^{\text {st }}$ run, in orange $\rightarrow 2^{\text {nd }}$ run, green $\rightarrow 3^{\text {rd }}$ run, black). For each system, the catalytic activities of two different samples (i.e., independent batches) are represented by solid lines ( $\left.\mathrm{S}_{1}\right)$ or dotted lines ( $\left.\mathrm{S}_{2}\right)$. Detail (c) and (d) are partly reproduced in the main document (the catalytic performance of the S1-series of sample is shown only) as Figure $5 c$ and Figure $5 d$, respectively. 


\begin{tabular}{|c|c|c|c|c|c|}
\hline $\mathbf{M}_{1}, \mathbf{M}_{2}$ & $\begin{array}{c}\text { No. } \\
\text { S }\end{array}$ & $\mathrm{SA}\left(\mathrm{m}^{2} / \mathrm{g}\right)$ & $\mathbf{1}^{\text {st }}$ run & $\begin{array}{l}\mathbf{T}_{50 \%}\left({ }^{\circ} \mathrm{C}\right) \\
2^{\text {nd }} \text { run }\end{array}$ & $3^{\text {rd }}$ run \\
\hline \multirow{2}{*}{$\varnothing$} & $\mathrm{S}_{1}$ & 56 & 249 & 284 & 286 \\
\hline & $\mathrm{S}_{2}$ & 53 & 300 & 302 & 301 \\
\hline \multirow{2}{*}{$\mathrm{Au}$} & $\mathrm{S}_{1}$ & 52 & 172 & 192 & 197 \\
\hline & $\mathrm{S}_{2}$ & 51 & 156 & 176 & 190 \\
\hline \multirow{2}{*}{$\mathrm{Au}, \mathrm{Pd}$} & $\mathrm{S}_{1}$ & 50 & 157 & 169 & 169 \\
\hline & $\mathrm{S}_{2}$ & 51 & 152 & 164 & 169 \\
\hline \multirow{2}{*}{$\mathrm{Au}, \mathrm{Cu}$} & $\mathrm{S}_{1}$ & 51 & 137 & 154 & 164 \\
\hline & $\mathrm{S}_{2}$ & 47 & 132 & 148 & 156 \\
\hline
\end{tabular}

Table S4. BET surface areas (SA) of the MgO-supported catalysts and corresponding temperatures of half-conversion $\left(\mathrm{T}_{50 \%}\right)$ extracted from the conversion curves in Figure $S_{7}$. $\mathrm{S}_{1}$ and $\mathrm{S}_{2}$ refer to different preparations of given materials.

\begin{tabular}{|c|c|c|c|c|c|}
\hline$M_{1}, M_{2}$ & $\begin{array}{c}\text { No. } \\
\text { S }\end{array}$ & $\mathrm{SA}\left(\mathrm{m}^{2} / \mathrm{g}\right)$ & $1^{\text {st }}$ run & $\begin{array}{c}\mathrm{T}_{50 \%}\left({ }^{\circ} \mathrm{C}\right) \\
2^{\text {nd }} \text { run }\end{array}$ & $3^{\text {rd }}$ run \\
\hline \multirow{2}{*}{$\varnothing$} & $S_{1}$ & 2 & 295 & 299 & 300 \\
\hline & $\mathrm{S}_{2}$ & 2 & 299 & 308 & 310 \\
\hline \multirow{2}{*}{$\mathrm{Au}$} & $\mathrm{S}_{1}$ & 2 & 218 & 212 & 227 \\
\hline & $\mathrm{S}_{2}$ & 3 & 199 & 222 & 216 \\
\hline \multirow{2}{*}{$\mathrm{Au}, \mathrm{Pd}$} & $\mathrm{S}_{1}$ & 2 & 169 & 182 & 184 \\
\hline & $\mathrm{S}_{2}$ & 2 & 164 & 183 & 177 \\
\hline \multirow{2}{*}{$\mathrm{Au}, \mathrm{Cu}$} & $\mathrm{S} 1$ & 2 & 206 & 217 & 215 \\
\hline & $\mathrm{S}_{2}$ & 2 & 205 & 209 & 207 \\
\hline
\end{tabular}

Table $\mathrm{S}_{5}$. BET surface areas (SA) of the YSZ-supported catalysts and corresponding temperatures of half-conversion ( $\left.\mathrm{T}_{50} \%\right)$ extracted from the conversion curves in Figure S8. S1 and S2 refer to different preparations of given materials. 

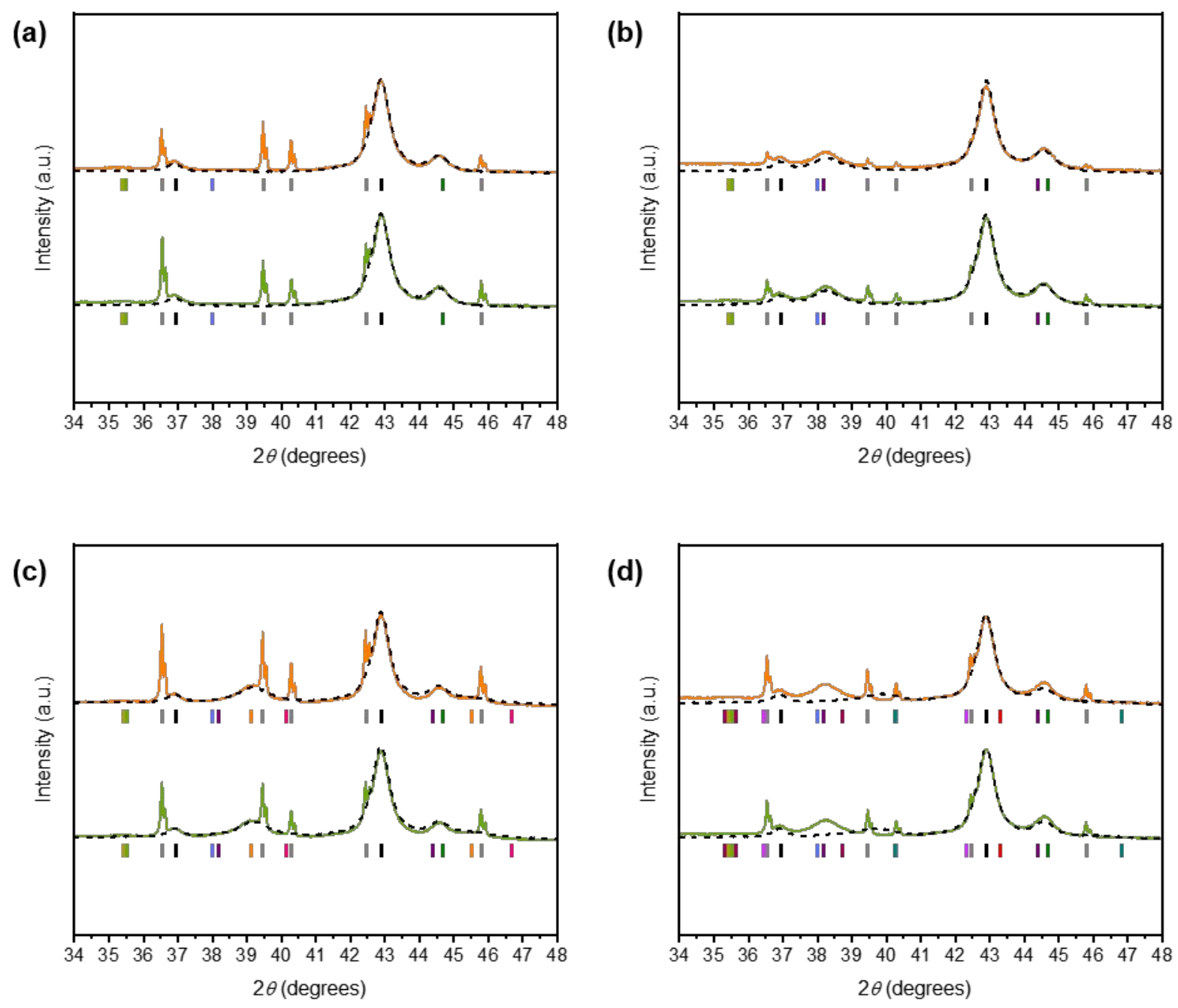

Figure S9. XRD patterns of the mechanochemically synthesized catalysts before (dashed black lines) and after three consecutive runs of the catalytic reaction (solid colored lines). In order: $\mathrm{MgO}$ (a), $\mathrm{Au} / \mathrm{MgO}(\mathrm{b}), \mathrm{Au}-\mathrm{Pd} / \mathrm{MgO}$ (c), $\mathrm{Au}-$ $\mathrm{Cu} / \mathrm{MgO}(\mathrm{d})$. The patterns are limited to the $34^{\circ}$ to $48^{\circ} 2 \theta$-range to enhance the clarity of the picture. Reproducibility was assessed by comparing the results on two independent preparations of the same material (i.e., S1 and S2). For each system, the first sample $\left(\mathrm{S}_{1}\right)$ is then designed with an orange theme and the second sample $\left(\mathrm{S}_{2}\right)$ with a green theme. Reference peaks color guide: $\bullet \mathrm{MgO}, \bullet \mathrm{Mg}(\mathrm{OH})_{2}, \bullet \mathrm{Fe}, \bullet \mathrm{MgFe}_{2} \mathrm{O}_{4}, \bullet \mathrm{Fe}_{3} \mathrm{O}_{4}, \bullet \mathrm{Au}, \bullet \mathrm{Au}-\mathrm{Pd}, \bullet \mathrm{Pd}, \bullet \mathrm{Au}-\mathrm{Cu}, \bullet \mathrm{Cu}, \bullet \mathrm{Cu} \mathrm{O} \bullet \mathrm{CuO} \bullet$ $\mathrm{SiO}_{2}$ (quartz). The quartz reflections are attributed to the quartz used to dilute the samples used for catalysis, which cannot fully be separated from the sample after the catalytic runs. 

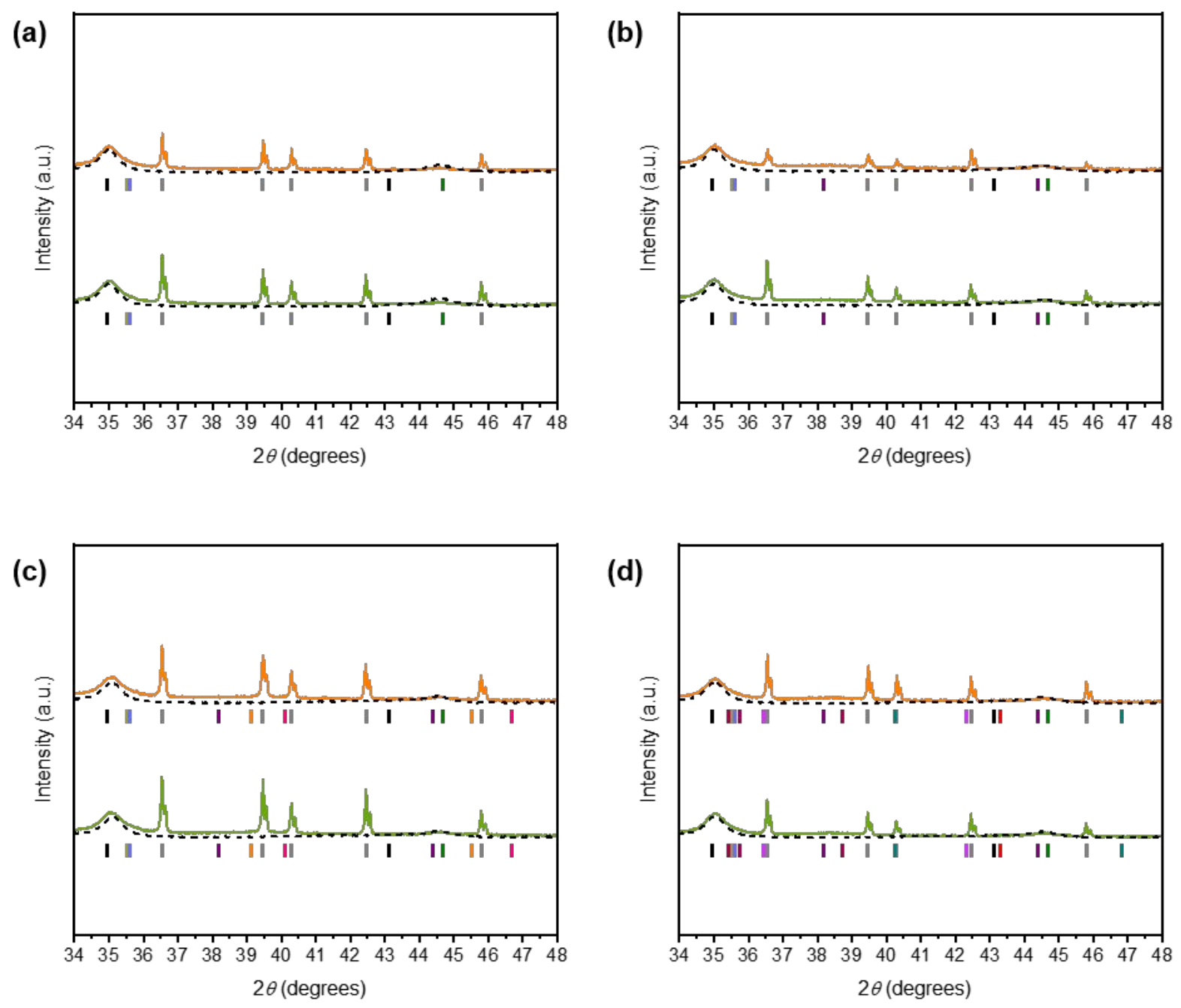

Figure S1o. XRD patterns of the mechanochemically synthesized catalysts before (dashed black lines) and after three consecutive runs of the catalytic reaction (solid colored lines). In order: YSZ (a), Au/YSZ (b), Au-Pd/YSZ (c), Au-Cu/YSZ (d). The patterns are limited to the $34^{\circ}$ to $48^{\circ} 2 \theta$-range to enhance the clarity of the picture. Reproducibility was assessed by comparing the results on two independent preparations of the same material (i.e., S1 and S2). For each system, the first sample $\left(\mathrm{S}_{1}\right)$ is then designed with an orange theme and the second sample $\left(\mathrm{S}_{2}\right)$ with a green theme. Reference peaks color guide: $\bullet \mathrm{YSZ}, \bullet \mathrm{Fe}, \bullet \mathrm{Fe}_{3} \mathrm{O}_{4}, \bullet \mathrm{Fe}_{2} \mathrm{O}_{3}, \bullet \mathrm{Au}, \bullet \mathrm{Au}-\mathrm{Pd}, \bullet \mathrm{Pd}, \bullet \mathrm{Au}-\mathrm{Cu}, \bullet \mathrm{Cu}, \bullet \mathrm{Cu}_{2} \mathrm{O}, \bullet \mathrm{CuO}, \bullet \mathrm{SiO}_{2}$ (quartz). The quartz reflections are attributed to the quartz used to dilute the samples used for catalysis, which cannot fully be separated from the sample after the catalytic runs. 